Semiconductor rivalry

\section{US bid to equal Japanese}

\section{Washington}

THE beleagured US semiconductor industry, hard pressed by superior manufacturing technologies from Japan, hopes to regain its competitive edge in world trade through a major cooperative manufacturing enterprise called Sematech. The Semiconductor Industry Association (SIA) will meet next week in Long Beach, California to give formal approval to the "manufacturing excellence project" that is already getting strong encouragement from US government.

Warren Davis of SIA says the industry's plight stems from the inability to develop effective manufacturing technologies for implementing innovative semiconductor designs. Davis believes no single US company is capable of taking on the scale of project needed for creating a new generation of manufacturing technologies.

Since early summer, representatives of the semiconductor industry have been holding discussions among themselves and with government officials on how best to proceed with Sematech. Some companies would like to see a full-scale manufacturing project, with the manufacturing muscle to beat the Japanese. Others would like a smaller pilot programme, with the technical fruits falling to individual companies. A compromise between the two approaches is likely.

Concern in Washington has been growing about the health of the US semiconductor industry, with several recent reports raising national security alarms over availability of semiconductor products (see Nature 323, 483; 1986). Davis says if Sematech is to work, the government will have to give assurances that the effort will not be hindered by antitrust prosecution or unfavourable tax status. Referring to the Sematech project, Bruce Merrifield, assistant secretary of commerce for productivity, technology and innovation has spoken enthusiastically about the government's role as "the catalytic element of change", eliminating potential barriers to success. SIA officials were in Washington last week for talks with Merrifield and National Science Foundation (NSF) director Erich Bloch concerning Sematech. Although no government funds have been committed to the project as yet, commitments on taxes and antitrust issues could be worth millions of dollars. The Semiconductor Research Corporation, an industry supported consortium, recently received a grant worth $\$ 1.2$ million from NSF and the Department of Defense, and could be a conduit for additional government funds.

Ozone depletion

\title{
US gets tough on CFC emissions
}

\section{Washington}

THE US government startled environmental conservatives and delighted radicals last week by calling for a complete halt to global emissions of halogenated alkanes thought to be destroying stratospheric ozone. The proposal was made in a paper on principles for an international protocol for protection of the stratospheric ozone layer issued by the State Department.

The United States will take the proposal as a starting position for the international negotiations beginning at Geneva on 1 December intended to put flesh on the bones of the Vienna Convention on Protection of the Ozone Layer. The convention has been signed by 25 countries since March 1985, but negotiations on a protocol to implement controls on chloro-

\section{Deaths foretold}

\section{Washington}

An extra 40 million skin cancer cases and 800,000 deaths among people now alive and those born before 2074 are likely in the United States if CFCs are not further controlled, according to EPA's draft study* of stratospheric modification. The predictions stem from the expected increase in ultraviolet-B radiation reaching the Earth's surface as stratospheric ozone declines. The EPA study is largely responsible for the tough new US position on emission controls.

The predictions assume annual growth of 2.5 per cent for CFCs and 0.6 per cent for carbon dioxide, in line with current estimates. They also assume a continuation of present growth rates of nitrous oxide and methane ( 0.25 per cent and 1 per cent respectively). Equilibrium global temperature would under these conditions increase by between 3 and 9.5 degrees celsius by 2075 , assuming the National Academy of Sciences' estimate of a 3 degree rise from a doubling of carbon dioxide.

EPA says that, as well as increasing skin cancers and cataracts, the increase of ultraviolet-B could promote the spread of herpes and leishmaniasis. There may also be effects on aquatic food chains and terrestrial plants, although information is scanty. But the study shows that estimates of risks are highly sensitive to CFC and halon growth rates; if the $\mathrm{CFC}$ growth rate is halved from 2.5 per cent to 1.2 per cent, estimated damage is reduced by 90 per cent. If a growth rate of 3.8 per cent is assumed, estimated damages increase by 400 per cent.

Tim Beardsley

An Assessment of the Risks of Stratospheric Modification (final draft), submission to EPA Science Advisory Board, October 1986. fluorocarbon (CFC) emissions have been postponed until the completion of informal technical meetings.

Anxiety about damage to the ozone layer, which filters out high-frequency ultraviolet radiation from the Sun, has grown in recent months. A 'hole' in the ozone layer appearing over Antarctica during the Antarctic winter (see Nature 321, 729; 1986 and 315, 207; 1985) is just now the subject of a study mounted by an inter-agency US team.

Although the cause of the 'hole' is not definitely known, the team's preliminary observations suggest that "a chemical mechanism is fundamentally responsible for the formation of the hole". Global ozone cover is thought to have decreased by $2-3$ per cent in $1970-80$, although measurements have been hard to interpret. CFCs also contribute to the greenhouse effect, by which the lower atmosphere may be warmed because of the effects of pollutants on the atmospheric radiation balance.

According to the State Department's proposal, a "long-term scheduled phaseout" of emissions should follow a nearterm freeze on emissions of all fully halogenated alkanes. These include the widely used chlorofluorocarbons CFC 11, 12 and 113 , believed to be the worst offenders, and halons 1211 and 1301. The proposal says that present uncertainties preclude the definition of a safe level of emissions, but that given the risks to health and the environment, the measures are justified. The proposed progressive reductions would be subject to change in the light of accumulating data.

The US proposal mentions in passing the need to develop incentives to persuade non-signatories of the convention to participate in the protocol.

The US industry group of chlorofluorocarbon manufacturers, the Alliance for Responsible CFC Policy, claims that the US proposal is not based on scientific principles. The alliance has proposed a cap on CFC production capacity and voluntary emission reduction measures to meet concern about the ozone layer.

The US proposal was based at least in part on a draft study by the Environmental Protection Agency, which estimates that incidence of skin cancer could increase significantly if emissions continue unchecked. But the industry alliance points out that the study has not yet been formally reviewed by the agency's scientific advisory board. A spokesman said that a phasing out of emissions did not necessarily mean an end to production, if some means could be devised to return CFCs to manufacturing plants for reuse.

Tim Beardsley 